Научная статья

УДК 330

DOI: $10.17213 / 2075-2067-2021-6-159-169$

\title{
СОЦИАЛЬНО-ЭКОНОМИЧЕСКОЕ РАЗВИТИЕ КАК ФУНДАМЕНТАЛЬНЫЙ ФАКТОР, ОТРАЖАЮЩИЙ КАЧЕСТВО УРОВНЯ ЖИЗНИ НАСЕЛЕНИЯ: ПРОБЛЕМЫ И ПУТИ РЕШЕНИЯ
}

\section{Максим Александрович Бондарев ${ }^{1 凶}$, Екатерина Евгеньевна Яковлева ${ }^{2}$, Марина Леонидовна Альпидовская ${ }^{3}$}

1, 2, 3 Финансовый университет при Правительстве РФ, Москва, Россия

${ }^{1}$ bondarrr2001@yandex.ru ${ }^{\bowtie}$, ORCID:0000-0001-8684-6020,SPIN-кod: 6806-3079

2prostoekaterinayakovleva@yandex.ru, ORCID: 0000-0003-2693-4058, SPIN-код: 1468-6000

${ }^{3}$ morskaya67@bk.ru, ORCID:0000-0001-9075-9683, SPIN-код: 1958-7585

Аннотация. Целью исследования является проведение анализа эффективности использования имеющихся ресурсов для обеспечения устойчивой соџиально-экономической политики государства. Достижение поставленной цели потребовало решения комплекса задач: сформировать понимание ключевых особенностей функционирования сочиально-экономической системы, проанализировать агрегированную статистическую информачию на основе различных источников, обосновать взаимосвязь между показателями доходов и расходов граждан, а также темпов инфляции с одной стороны и уровнем жизни населения - $с$ другой.

Методология исследования. В данной статье использованы традиионные методы исследования: системный анализ, дедукиия, индукция, ситуационный анализ, аналогия и диалектика.

Результаты исследования. Базовыми факторами, определяющиим уровень благосостояния населения, которые в свою очередь отражают качество проводимой в стране сочиально-экономической политики, являются уровень доходов населения, а также демографическая статистика. Было доказано, что главная задача сочиально-экономической политики государства - это обеспечение уверенности граждан в завтрашнем дне. Она должна представлять собой комплекс мер, обеспечиваюших исполнение естественных прав человека за счёт реального сектора экономики и перераспределения имеюшихся средств.

Перспективу исследования на сегодняшний день составляет проблема регулирования и обеспечения сочиильно-экономической политики государства. Она имеет первостепенное значение с точки зрения дальнейших перспектив повышения уровня жизни населения. Данная работа представляет научный интерес для широкого круга специалистов и аналитиков. Помимо этого, информащия, представленная в статье, может выступать научной базой для моделирования и прогнозирования приоритетных направлений социильно-экономического развития странь.

Ключевые слова: сочиально-экономическая политика, уровень благосостояния населения, среднедушевые доходы населения, демографическая статистика, коэффициент дисконтирования, суммарный коэффищиент рождаемости

Для цитирования: Бондарев М.А., Яковлева Е.Е., Альпидовская М.Л. Социальноэкономическое развитие как фундаментальный фактор, отражающчий качество уровня жизни населения: проблемы и пути решения // Вестник Южно-Российского

(C) Бондарев М.А., Яковлева Е.Е., Альпидовская М. Л., 2021 
государственного технического университета. Серия: Социально-экономические науки. 2021. T. 14, № 6. C. 159-169. http://dx.doi.org/10.17213/2075-2067-2021-6-159-169.

Original article

\title{
SOCIO-ECONOMIC DEVELOPMENT AS FUNDAMENTAL FACTOR REFLECTING THE QUALITY OF THE STANDART OF LIVING OF THE POPULATION: PROBLEMS AND SOLUTIONS
}

\author{
Maxim A. Bondarev ${ }^{\square}$, Ekaterina E. Yakovleva ${ }^{2}$,Marina L. Alpidovskaya ${ }^{3}$ \\ ${ }^{1,2,3}$ Financial University under the Government of Russia, Moscow, Russia \\ ${ }^{11}$ bondarrr2001@yandex.ru ${ }^{\bowtie}$,ORCID:0000-0001-8684-6020, SPIN: 6806-3079 \\ 2prostoekaterinayakovleva@yandex.ru,ORCID:0000-0003-2693-4058,SPIN: 1468-6000 \\ ${ }^{3}$ morskaya67@bk.ru, ORCID:0000-0001-9075-9683, SPIN: 1958-7585
}

Abstract. The purpose of the study is to analyze the effectiveness of the use of available resources to ensure a sustainable socio-economic policy of the state. Achieving this goal required solving a set of tasks: to form an understanding of the key features of the functioning of the socioeconomic system, to analyze aggregated statistical information based on various sources, to substantiate the relationship between the indicators of income and expenses of citizens, as well as inflation rates on the one hand and the standard of living of the population on the other.

Research methodology. This article uses traditional research methods: system analysis, deduction, induction, situational analysis, analogy and dialectics.

The results of the study. The basic factors determining the level of well-being of the population, which in turn reflect the quality of the socio-economic policy pursued in the country, are the level of income of the population, as well as demographic statistics. It has been proved that the main task of the socio-economic policy of the state is to ensure the confidence of citizens in the future. It should be a set of measures ensuring the fulfilment of natural human rights at the expense of the real sector of the economy and the redistribution of available funds.

The perspective of the study today is the problem of regulating and ensuring the socio-economic policy of the state. It is of paramount importance from the point of view of further prospects for improving the standard of living of the population. This work is of scientific interest to a wide range of specialists and analysts. In addition, the information presented in the article can serve as a scientific basis for modeling and forecasting priority areas of socio-economic development of the country.

Keywords: socio-economic policy, level of well-being of the population, average per capita income of the population, demographic statistics, discount coefficient, total fertility rate

For citation: Bondarev M.A., Yakovleva E. E., Alpidovskaya M. L. Socio-economic development as fundamental factor reflecting the quality of the standart of living of the population: problems and solutions // Bulletin of the South Russian State Technical University. Series: Socio-economic Sciences. 2021; 14(6): 159-169. (In Russ.). http://dx.doi.org/10.17213/20752067-2021-6-159-169.

Введение. Основным фактором, обеспечивающим устойчивое развитие экономики государства, выступает совокупность количественных и качественных показателей, определяющих уровень жизни населения. К таким показателям относят: уровень дохода домашних хозяйств, который позволяет им приобретать те или иные товары и услуги; 
Вестник ЮРГТУ (НПИ). Серия: Сочиально-экономические науки. 2021 г. T. 14. № 6 Bulletin of the SRSTU (NPI). Series: Socio-Economic Sciences. 2021. Vol. 14. № 6

объём сбережений, находящихся в распоряжении домохозяйств; показатель расходов населения и объём потребления материальных благ и услуг; дифференциацию доходов населения; уровень границ бедности; социальнодемографическую статистику и т.д. Рассмотрим некоторые из перечисленных показателей на примере Российской Федерации.

Доходы населения. Прежде всего, структуру доходов населения составляют: заработная плата наёмных работников и доходы предпринимателей; доходы, получаемые от использования и распоряжения собственностью; социальные выплаты, включающие пенсии, стипендии и т.д.; доходы от инвестиционной деятельности и т.п.

На основе данных официальной статистики рассмотрим следующий график (рис. 1)1.

В ходе анализа представленного графика можно заметить восходящую линию тренда среднедушевых доходов населения. Её можно будет увидеть и при детальном рассмотрении среднедушевого дохода населения по субъектам РФ. Однако прежде чем давать какие-либо комментарии касательно роста доходов населения, проведём некоторые расчёты. В экономической статистике часто используется такой показатель, как дисконтирование (приведение всех данных к определённому моменту времени). Таким образом, возможно рассчитать эквивалент текущих доходов граждан их доходам, например, в 2013 году (табл. 1)2.

Уровень инфляции показывает, на сколько процентов обесценивается каждый рубль за год. Таким образом, чтобы приобрести товар в конце 2013 года (без учёта снижения его стоимости за счёт устаревания и т.п.), нам понадобится сумма на $6,45 \%$ больше, чем в начале года. На основе этого суждения рассчитаем коэффициент дисконтирования путём перемножения сумм ставок инфляции и единицы:

Таблица 1

Table 1

Уровень инфляции в РФ по годам, \% Inflation rate in the Russian Federation by year, \%

\begin{tabular}{|c|c|c|c|c|c|c|c|}
\hline 2013 & 2014 & 2015 & 2016 & 2017 & 2018 & 2019 & 2020 \\
\hline 6,45 & 11,36 & 12,91 & 5,38 & 2,52 & 4,27 & 3,05 & 4,91 \\
\hline
\end{tabular}

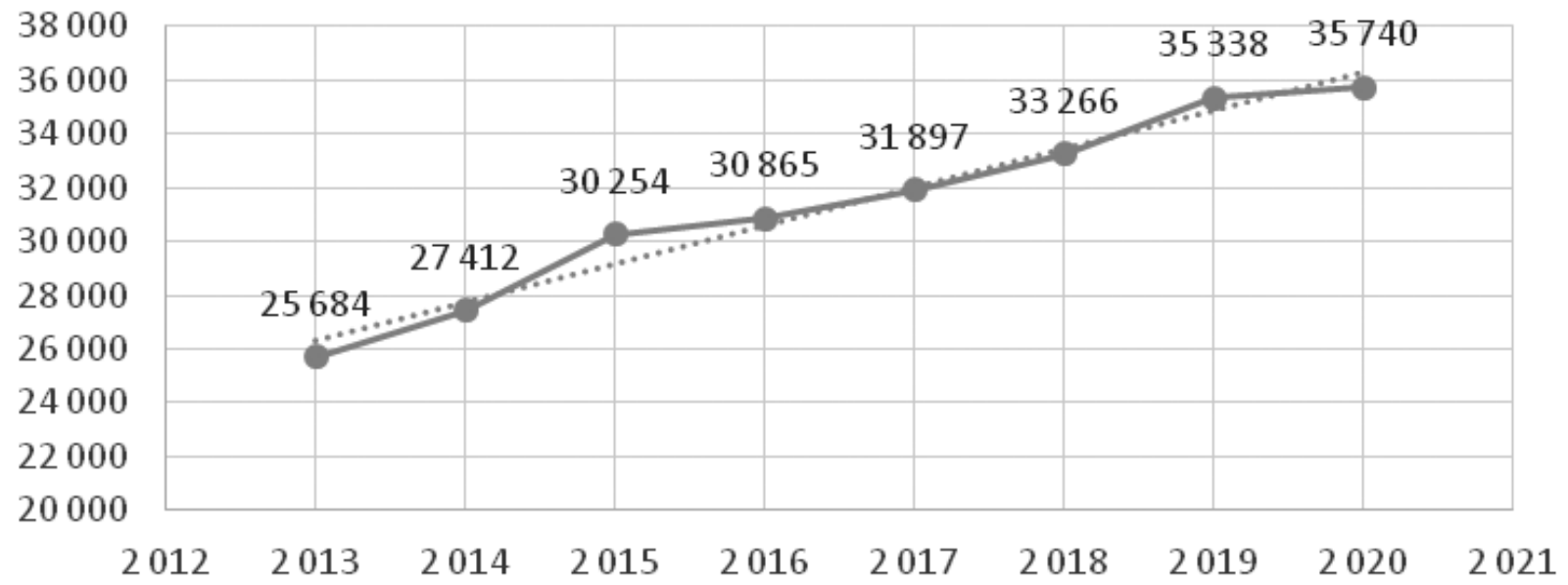

Рис. 1. Среднедушевые доходы населения РФ по годам, руб.

Fig. 1. Average per capita income of the population of the Russian Federation by year, rub.

1 Среднедушевой доход населения: динамика, расчёт [Электронный ресурc]. URL: https://rosinfostat.ru/ srednedushevoj-dohod/ (дата обращения: 09.10.2021).

2 Инфляция в России. Таблицы уровня инфляции [Электронный ресурс]. URL: https://yровень-инфляции. рф/таблицы-инфляции (дата обращения: 09.10.2021). 
$(1+0,0645) \times(1+0,1136) \times(1+0,1291) \times$ $\times(1+0,0538) \times(1+0,0252) \times(1+0,0427) \times$ $\times(1+0,0305) \times(1+0,0491)=1,63004$.

Значит, рубль обесценился с 2013 по 2020 год в 1,63004 раза. Таким образом, эквивалент среднедушевой заработной платы за 2020 год к 2013 году составит:

$$
35740 / 1,63004=21925,84 \text { руб. }
$$

Выходит, что среднедушевой доход населения с учётом инфляции сократился. Такая тенденция вызвана влиянием множества факторов. На сокращение эквивалентного дохода существенное влияние оказала внезапно возникшая пандемия 2019-го года, вызвавшая прирост уровня инфляции в 2020 году, а также массовое банкротство множества организаций. Помимо этого, на уровень доходов граждан за эти годы влияли сокращение спроса на отдельные виды продукции РФ в связи с неустойчивой политической ситуацией и рядом направленных против нашей страны санкций, относительно высокая волатильность цен на нефть и нефтепродукты и т.д.
Также хотелось бы отметить, что, хотя рассмотренный выше показатель и признан одним из основных отражающих текущие доходы граждан, на наш взгляд, приведённые значения весьма условны, ведь среднедушевой доход населения рассчитывается путём деления годового объёма денежных доходов на среднегодовую численность населения. Так, например, рассмотрим значения этого показателя не по РФ в целом, а по федеральным округам (рис. 2) 3 .

Невооружённым взглядом можно заметить, что доходы в Центральном ФО и, например, Приволжском ФО отличаются почти в 2 раза. Так, расчёт среднего значения дохода по стране становится в значительной мере округлённым и весьма неточным.

Расходы населения. По структуре расходов населения можно определить уровень его благосостояния. Основываясь на многократно подтверждённом на практике законе Энгеля, который гласит: «...чем беднее семья, тем выше доля расходов на продовольствие...» и, соответственно, наоборот: «...чем богаче семья, тем выше доля расходов на ценные блага...», проанализируем следующую таблицу (см. табл. 2) $)^{4}$.

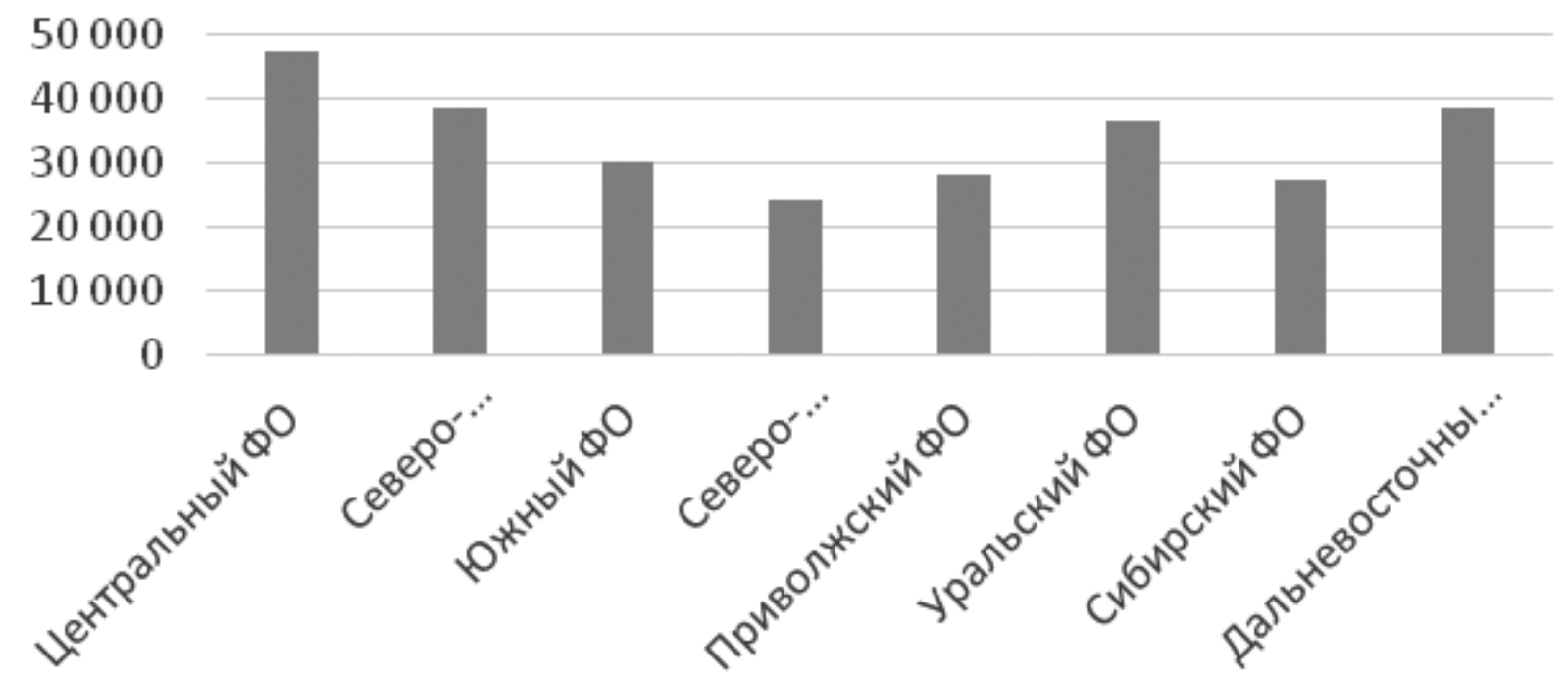

Рис. 2. Среднегодовой доход населения по федеральным округам, руб.

Fig. 2. Average annual income of the population by federal districts, rub.

3 Среднедушевые денежные доходы населения по субъектам Российской Федерации (новая методология) [Электронный ресурс]. URL: https://rosstat.gov.ru/folder/13397?print=1 (дата обращения: 09.10.2021).

4 Федеральная служба государственной статистики. Уровень жизни. Доходы и расходы домашних хозяйств на потребление, уровень и структура располагаемых ресурсов домашних хозяйств различных социально-экономических категорий [Электронный ресурс]. URL: https://rosstat.gov.ru/folder/13397 (дата обращения: 09.10.2021). 


\section{Структура потребительских расходов домашних хозяйств в зависимости от уровня среднедушевых располагаемых ресурсов по годам, \% Structure of household consumer spending depending on the level of per capita disposable resources by year, \%}

\begin{tabular}{|l|c|c|c|c|c|c|c|c|c|}
\hline \multirow{2}{*}{ Расходы на: } & 2013 & 2014 & 2015 & 2016 & 2017 & 2018 & 2019 & 2020 \\
\cline { 2 - 9 } & \multicolumn{7}{|c|}{ Доля расходов в общей её структуре } \\
\hline $\begin{array}{l}\text { продукты питания и } \\
\text { безалкогольные напитки }\end{array}$ & 27,7 & 28,5 & 32,1 & 32,3 & 31,6 & 30,7 & 29,7 & 33,2 \\
\hline $\begin{array}{l}\text { организацию отдыха и } \\
\text { культурные мероприятия }\end{array}$ & 7,2 & 7,1 & 6,7 & 6,7 & 7 & 7,8 & 8,4 & 5,8 \\
\hline
\end{tabular}

Как видно из данных таблицы, расходы на продукты питания возросли на 4,6 процентных пункта в период с 2013 по 2016 годы, что объясняется валютным кризисом 2014 2015 годов, в ходе которого населению было свойственно сохранять денежные средства в качестве сбережений в целях обеспечения своих трат в будущем. В последние же годы доля расходов на продукты первой необходимости имеет тенденцию к снижению. В свою очередь, доля затрат на организацию досуга постепенно возрастает последние 5 лет (не считая 2020 год с установленными локдаунами и ограничениями и, как следствие, банкротство большого количества предприятий и временную потерю многими домашними хозяйствами основных источников доходов, а также ограничения в сфере туризма). Всё это может служить основой для вывода о том, что уровень благосостояния населения нашей страны постепенно возрастает, граждане могут позволить себе тратить больше средств на отдых и приобретение ценных благ.

Стоит отметить, что такая тенденция вызвана отнюдь не ростом доходов граждан, а лишь увеличением объёма выданных кредитов [1]. Причём общая сумма займов за первый квартал 2021 года увеличилась по сравнению с аналогичными периодами 2019 и 2020 годов и составила около 20,8 трлн. рублей, что является рекордным пока- зателем. Известное аналитическое агентство Frank RG провело подсчёты и выяснило, что за первые месяцы 2021 года физическим лицам было выдано почти 4,2 трлн. руб. займов (на 50\% больше, чем в 2020 и 2021 годы), причём в апреле был установлен новый месячный рекорд - 1,3 трлн. руб., что на $178 \%$ больше, чем в апреле 2020 года 5 . При этом, по заявлению Национального бюро кредитных историй, высокими темпами растёт и объём просроченных потребительских кредитов. Таким образом, проблема закредитованности населения с каждым годом всё ухудшается.

Эти и многие другие показатели в той или иной мере отражают уровень благосостояния населения, однако важной также является и оценка самим населением своего финансового положения (табл. 3$)^{6}$.

Данные таблицы 3 позволяют делать вывод о том, что в целом последние 4-5 лет финансовое положение населения улучшается. Это обусловлено резким ростом доли домохозяйств, которые способны позволить себе приобретение товаров длительного пользования (на наш взгляд, именно эта категория граждан и составляет средний класс), и устойчивым сокращением доли граждан, которым не хватает денег даже на пропитание (часть населения, которая находится за чертой бедности). Однако, несмотря на улучше-

5 Новостной портал «Московский Комсомолец». Установлен новый рекорд закредитованности россиян [Электронный ресурс]. URL: https://www.mk.ru/economics/2021/05/24/ustanovlen-novyy-rekord-zakreditovannostirossiyan.html (дата обращения: 07.10.2021).

6 Федеральная служба государственной статистики. Уровень жизни. Доходы, расходы и сбережения населения [Электронный ресурс]. URL: https://rosstat.gov.ru/folder/13397?print=1 (дата обращения: 12.10.2021). 


\section{Оценка своего финансового положения домашними хозяйствами, в \% ко всем домохозяйствам Assessment of their financial situation by households, in \% to all households}

\begin{tabular}{|l|c|c|c|c|c|c|c|c|}
\hline $\begin{array}{c}\text { Домохозяйства, оценившие } \\
\text { свое финансовое положение } \\
\text { следующим образом: }\end{array}$ & 2013 & 2014 & 2015 & 2016 & 2017 & 2018 & 2019 & 2020 \\
\hline Не хватает денег даже на еду & 1,2 & 1,1 & 1,2 & 1 & 0,9 & 0,7 & 0,4 & 0,2 \\
\hline $\begin{array}{l}\text { Затруднительно покупать одеж- } \\
\text { ду и оплачивать жилищно-ком- } \\
\text { мунальные услуги }\end{array}$ & 18,9 & 18,8 & 19,4 & 20,5 & 19,2 & 14,6 & 13,1 & 12,5 \\
\hline $\begin{array}{l}\text { Не могут позволить покупку то- } \\
\text { варов длительного пользования }\end{array}$ & 45,3 & 45 & 45,3 & 47,6 & 49,5 & 48,3 & 48,6 & 48,1 \\
\hline $\begin{array}{l}\text { Не хватает денег на покупку ав- } \\
\text { томобиля, квартиры }\end{array}$ & 30,7 & 32 & 29,7 & 26,7 & 26,6 & 32,5 & 34,4 & 36,4 \\
\hline $\begin{array}{l}\text { Средств достаточно, чтобы ку- } \\
\text { пить все, что считают нужным }\end{array}$ & 3,2 & 2,6 & 2,4 & 3 & 2,9 & 3,2 & 2,9 & 2,6 \\
\hline Затруднились ответить & 0,8 & 0,5 & 2 & 1,2 & 0,9 & 0,7 & 0,5 & 0,2 \\
\hline
\end{tabular}

ние отдельных показателей, мы можем также наблюдать и относительно неизменный уровень показателя, отражающего долю населения, которое уже способно обеспечить себя самым необходимым, но при этом не может позволить приобретение товаров длительного потребления.

Демографическая статистика. К иным исследуемым показателям социально-экономического развития относят демографическую статистику (её можно определить как соотношение рождаемости и смертности, а также миграционными процессами) [3]. Известно, что в большинстве стран Европы популярно такое движение, как «чайлдфри» (childfree), когда люди сознательно выбирают свободу личности вместо рождения детей [4].

В то же время увеличился процент малышей, рождённых в неполных семьях, возросло число нетрадиционных браков, что по своей природе не приводит к воспроизводству населения, в результате чего формируется демографическое старение. Подчеркнём, что Интернет, телевидение и СМИ как средства формирования массовой культуры оказали огромное влияние на восприятие человеком окружающего мира, в том числе молодого поколения. Вместе с тем кинематографический образ нарушает традиционные ценности человеческой жизни. Данный шаблон поведения был навязан давным-давно и России.

По данным Росстата, на 2019 г. численность населения нашей страны достигла 146 млн. 780 тыс. чел., за 2020 г. этот показатель снизился до 510 тыс. чел. и составил на 1 января 2021 г. 146 млн. 238 тыс. чел. (табл. 4)7.

При этом в ряде регионов Северо-Западного, Центрального, Уральского, Северо-Кавказского федерального округов численность населения возросла главным образом за счёт миграционных процессов (табл. 5)

Стоит подчеркнуть, что уменьшение численности сельского населения напрямую свя-

7 Демография и уровень жизни в России по годам с 1897-2021 г. [Электронный ресурc]. URL: https://infotables. ru/statistika/31-rossijskaya-federatsiya/782-obshchaya-chislennost-naseleniya-rossii/ (дата обращения: 05.10.2021).

8 Рейтинг регионов по демографии - 2020 [Электронный pecypc]. URL: https://riarating.ru/ infografika/20200421/630168368.html/ (дата обращения: 05.10.2021). 
Численность населения России по годам

Table 4 Population of Russia by year

\begin{tabular}{|c|c|c|c|c|c|}
\hline \multirow[t]{2}{*}{ Годы } & \multirow{2}{*}{$\begin{array}{c}\text { Численность населения России, } \\
\text { млн. человек }\end{array}$} & \multicolumn{2}{|c|}{$\begin{array}{l}\text { В том числе, } \\
\text { млн. чел. }\end{array}$} & \multicolumn{2}{|c|}{$\begin{array}{c}\text { В общей численности } \\
\text { населения, } \%\end{array}$} \\
\hline & & городское & сельское & городское & сельское \\
\hline 2015 & $146267288 \uparrow$ & 108,3 & 38 & $74 \%$ & $26 \%$ \\
\hline 2016 & $146544710 \uparrow$ & 108,6 & 37,9 & $74 \%$ & $26 \%$ \\
\hline 2017 & $146804372 \uparrow$ & 109 & 37,8 & $74 \%$ & $26 \%$ \\
\hline 2018 & $146880432 \uparrow$ & 109,3 & 37,6 & $74 \%$ & $26 \%$ \\
\hline 2019 & $146780720 \downarrow$ & 109,5 & 37,3 & $75 \%$ & $25 \%$ \\
\hline 2020 & $146745098 \downarrow$ & 109,6 & 37,2 & $75 \%$ & $25 \%$ \\
\hline 2021 & $146238185 \downarrow$ & 109,3 & 36,9 & $75 \%$ & $25 \%$ \\
\hline \multicolumn{6}{|c|}{$\begin{array}{l}\text { Примечание. Данные по общей численности населения России приведены за } 2015 \text { г. и пос- } \\
\text { ледующие годы с учетом численности населения Республики Крым и г. Севастополя. } \\
2021 \text { год - это предварительная оценка численности постоянного населения на } 1 \text { января } \\
2021 \text { г. по расчету от 25.01.2021 г. }\end{array}$} \\
\hline
\end{tabular}

\section{Рейтинг регионов по демографии} Rating of regions by demography

\begin{tabular}{|l|c|}
\hline \multicolumn{1}{|c|}{ Регион } & Миграционный прирост \\
\hline Москва & 257,3 тыс. чел \\
\hline Санкт-Петербург & 106,8 тыс. чел \\
\hline Московская область & 298,7 тыс. чел \\
\hline Тюменская область & 46,9 тыс. чел \\
\hline Республика Татарстан & 11,7 тыс. чел \\
\hline
\end{tabular}

зано с увеличением миграции и низким уровнем рождаемости. К примеру, до революции в России были распространены крестьянские многодетные семьи. Дети помогали не только по хозяйству, но и являлись крепкой опорой в старости. При капиталистических отношениях женщина была впервые взята из семьи [2]. Она принимала активное участие в общественных делах наравне с мужчинами. Детский и женский труд в XVII-XIX вв. стали использовать чаще, т.к. появились первые механические станки [7], на них женщины и подростки выполняли работу быстрее и лучше и при этом за свой труд просили немного. В то время натуральное хозяйство сменяется частной собственностью, поэтому стало намного выгоднее приобретать необходимые вещи, нежели изготавливать их самим. К тому же мужчин-рабочих не становится меньше, они переходят в другие отрасли. Таким образом, некоторые виды производства становятся исключительно женскими, например, швейное или кружевное.

В наши дни женщина на первое место ставит карьеру, также нельзя исключить важность получения образования и самореализа- 
цию в жизни. Следует отметить, что от репродуктивного возраста женщины зависит число родившихся детей. Обращаясь к демографическому словарю, можно заметить, что его границы устанавливаются от 15-49 лет, но для государств с низким уровнем рождаемости - от 15-44 лет [6].

Благодаря данным федеральной службы государственной статистики, мы можем увидеть тенденцию суммарного коэффициента рождаемости (СКР). Таким образом, возраст женщины при рождении первого ребёнка достигает 30 лет и выше, в связи с чем сокращается уровень естественного прироста населения (рис. 3).

Например, суммарный коэффициент рождаемости в 2000 году составил 1,29\%, в 2011 году он вырос до 1,58\%, на протяжении последующих лет не уменьшался, достиг максимального уровня в 2015 году, но в 2018 году уменьшился до 1,58\%.

Второй момент, на который следует обратить внимание: женщины старшего возраста имеют более высокий риск рождения детей с генетической патологией. Основной фактор - старение яйцеклеток. В результате этого каждое последующее поколение менее здорово, чем родительское.
Безусловно, демографический кризис опасная проблема, которая может привести к непоправимым последствиям, однако выход для нашей страны есть. Важно перестроить систему, направленную на социально-экономическое развитие человека. К сожалению, сегодня теоретическая концепция достойного уровня жизни далека от совершенства. Такой наш вывод подтверждается неравенством доходов, высоким уровнем бедности, устойчивым ростом цен на потребительские товары, низким качеством медицинского обслуживания и т.п.

Выводы. Таким образом, на основе проведённого анализа массива данных, отражающих основные показатели благосостояния населения, можно подвести краткие итоги. Несмотря на то, что общий уровень жизни граждан вырос за последние годы, значительная часть населения всё ещё нуждается в социальной поддержке, а также в поддержке со стороны государства (различные социальные пособия, пенсии и т.п.). Для решения данной проблемы необходимо проводить политику, направленную на повышение уровня доходов граждан, особенно малообеспеченных семей. Для этого следу-

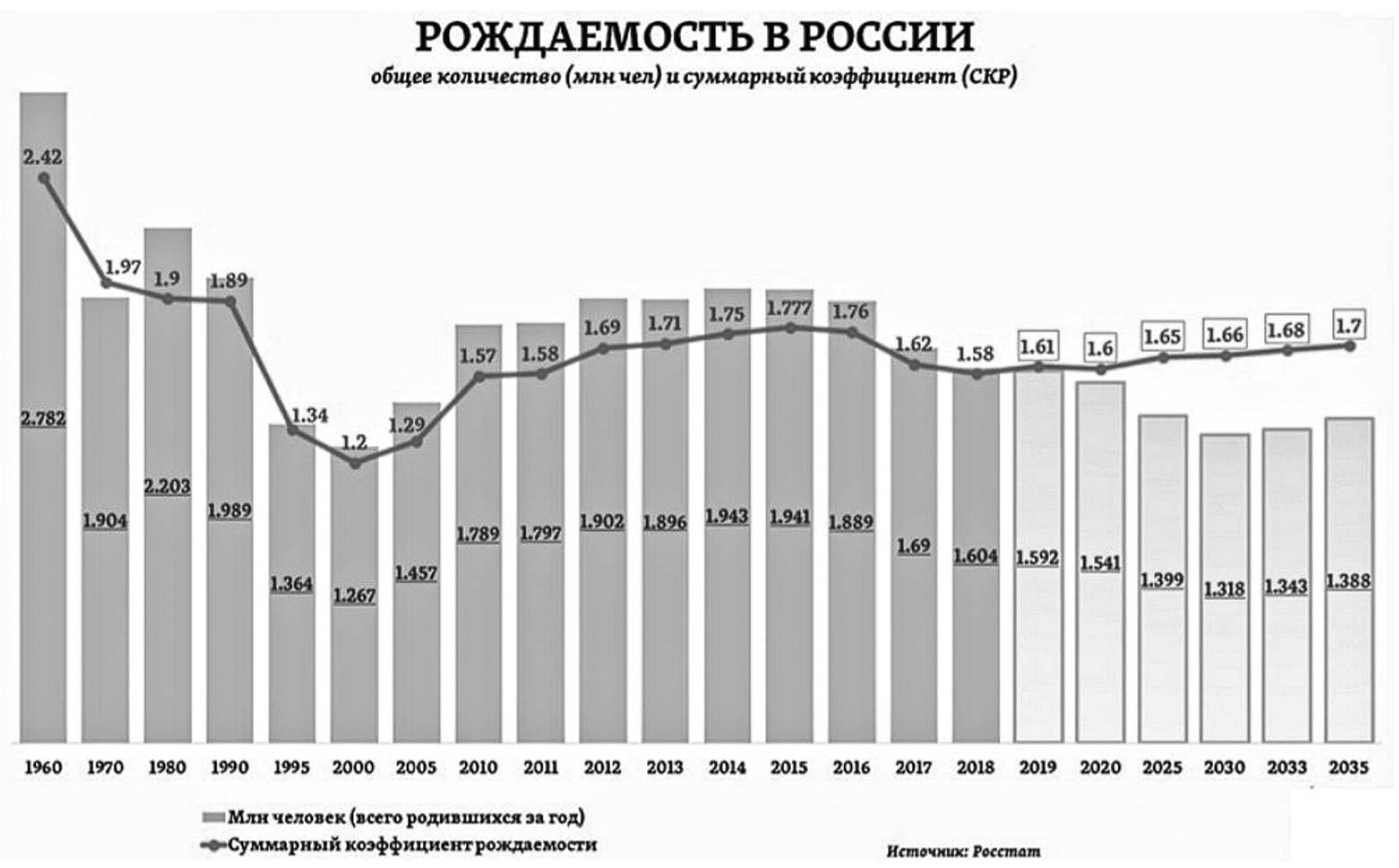

Рис. 3. Рождаемость в России, общее количество и коэффициент СКР [5]

Fig. 3. Birth rate in Russia, total number and TFR coefficient 
Вестник ЮРГТУ (НПИ). Серия: Сочиально-экономические науки. 2021 г. T. 14. № 6 Bulletin of the SRSTU (NPI). Series: Socio-Economic Sciences. 2021. Vol. 14. № 6

ет установить минимальный размер оплаты труда на уровне $50 \%$ от средней зарплаты (в РФ эта сумма составляет $25 \%$ средней 3/п), следует увеличить пособие по безработице в 2,5-3 раза, а сумма пенсии должна составлять около $40-50 \%$ от полной з/п. Данные нормы устанавливаются Международной организацией труда и приняты в большинстве развитых и развивающихся стран с уровнем средних доходов, аналогичным РФ. При этом повышение уровня доходов и пенсий граждан возможно за счёт свободных средств предприятий, так как их финансовый результат за последние годы увеличился на $70 \%$. Данные меры позволят избежать чрезмерных потерь бюджета и повысить уровень жизни населения.

Заключение. Стоит отметить, что главная задача социально-экономической политики государства - это обеспечение уверенности граждан в завтрашнем дне. Она должна представлять собой комплекс мер, обеспечивающих исполнение естественных прав человека за счёт реального сектора экономики и перераспределения имеющихся средств.

\section{Список источников}

1. Альпидовская М.Л. Записки о новой реальности: постижение глобальных замыслов: монография. М.: Прометей, 2021. 172 с.

2. Альпидовская М. Л., Соколов Д. П. Современные противоречия современной системы «хозяйствования» // Вестник ВолГУ. Сер. 3. Экономика. Экология. 2019. Т. 21. №2. C. 6-18.

3. Валентей Д.И. Демографический энциклопедический словарь. М.: Сов. Энциклопедия, $1985.607 \mathrm{c}$.

4. Голубова Т.Н., Махкамова 3.Р., Литвиненко А.И. Феномен «чайлдфри» и проблемы рождаемости в современной России// Таврический медико-биологический вестник. 2016. Т. 19. №4. С. 18-22.

5. Казенин К.И. Рождаемость в России в 2020 г.: региональная динамика // Экономическое развитие России. 2021. Т. 28. №3. C. $50-54$.

6. Медков В.М. Словарь демографических терминов. Демография. М., 2004. 575 с.
7. Михеичева В.Л.Условия труда фабрично-заводских рабочих в Российской империи в последней четверти XIX в. // Международный научный журнал «Инновационная наука». 2016. №2. С. 47-50.

\section{References}

1. Al'pidovskaja M.L. Zapiski o novoj real'nosti: postizhenie global'nyh zamyslov: monografija [Notes on a new reality: comprehension of global ideas: monograph]. Moscow: Prometej, 2021. 172 p. (In Russ.).

2. Al'pidovskaja M. L., Sokolov D. P. Sovremennye protivorechija sovremennoj sistemy «hozjajstvovanija» [Modern contradictions of the modern system of «management»]. Vestnik VolGU. Ser. 3. Jekonomika. Jekologija [Bulletin of the Volga. Ser. 3. Economy. Ecology]. 2019; 21(2): 6-18. (In Russ.).

3. Valentej D. I. Demograficheskij jenciklopedicheskij slovar' [Demographic Encyclopedic dictionary]. Moscow: Sov. Jenciklopedija, 1985. 607 p. (In Russ.).

4. Golubova T.N., Mahkamova Z.R., Litvinenko A. I. Fenomen «chajldfri» i problemy rozhdaemosti $\mathrm{v}$ sovremennoj Rossii [The phenomenon of «childfree» and problems of fertility in modern Russia]. Tavricheskij mediko-biologicheskij vestnik [Tauride medico-biological Bulletin]. 2016; 19(4): 18-22. (In Russ.).

5. Kazenin K. I. Rozhdaemost' v Rossii v 2020 g.: regional'naja dinamika [Birth rate in Russia in 2020: regional dynamics]. Jekonomicheskoe razvitie Rossii [Economic development of Russia]. 2021; 28(3): 50-54. (In Russ.).

6. Medkov V.M. Slovar' demograficheskih terminov. Demografija [Dictionary of Demographic terms. Demography]. Moscow, 2004. 575 p. (In Russ.).

7. Miheicheva V.L. Uslovija truda fabrichno-zavodskih rabochih $\mathrm{v}$ Rossijskoj imperii $\mathrm{v}$ poslednej chetverti XIX v. [Working conditions of factory workers in the Russian Empire in the last quarter of the XIX century]. Mezhdunarodnyj nauchnyj zhurnal "Innovacionnaja nauka» [International scientific journal «Innovative Science»]. 2016; (2): 47-50. (In Russ.). 
Статья поступила в редакиию 28.11.2021; одобрена после рецензирования 04.12.2021; принята к публикации 08.12.2021.

The article was submitted on 28.11.2021; approved after reviewing on 04.12.2021; accepted for publication on 08.12.2021.

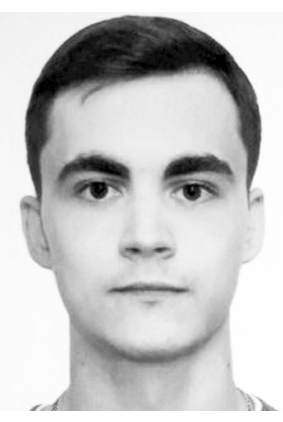

\section{ИНФОРМАЦИЯ ОБ АВТОРАХ}

Бондарев Максим Александрович - студент 3-го курса по программе бакалавриата, Финансовый университет при Правительстве Российской Федерации.

Россия, г. Москва, ул. Керченская, 1А, корп. 2

Maxim. A. Bondarev - 3rd year student in the Bachelor's degree program, Financial University under the Government of the Russian Federation.

1A Kerchenskaya st., bld. 2, Moscow, Russia

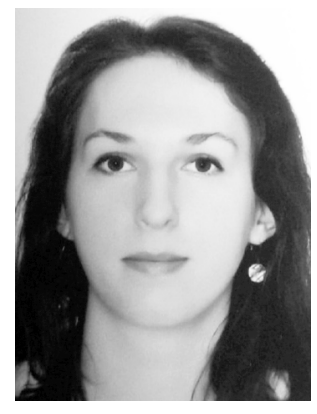

Яковлева Екатерина Евгеньевна - студент 3-го курса по программе бакалавриата, Финансовый университет при Правительстве Российской Федерации.

Россия, г. Москва, ул. Петрозаводская, 11, корп. 1, кв. 23

Ekaterina E. Yakovleva - 3rd year student in the Bachelor's degree program, Financial University under the Government of the Russian Federation.

11 Petrozavodskaya st., bld. 1, app. 23, Moscow, Russia

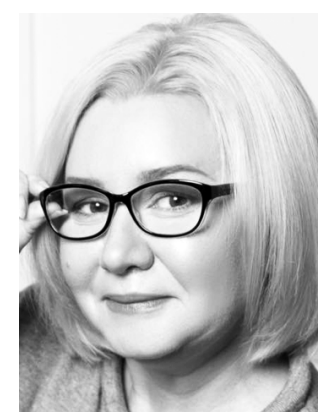

Альпидовская Марина Леонидовна - доктор экономических наук, профессор, профессор Департамента экономической теории, Финансовый университет при Правительстве Российской Федерации».

Россия, г. Москва, ул. Народного Ополчения, 54

Marina L. Alpidovskaya - Doctor of Economic Sciences, Professor, Professor of the Department of Economic Theory, Financial University under the Government of Russia Federation.

54 Narodnogo Opolcheniya st., Moscow, Russia 
Вклад авторов:

Бондарев М. А. - написание исходного текста; проведение статистического исследования; разработка методологии; анализ доходов населения, а такле совокупности факторов, влияющих на его изменение; итоговые выводы.

Яковлева Е.Е. - написание исходного текста; проведение статистического исследования; сбор и систематизация данных; анализ демографической статистики и расчёт базовых коэффициентов рождаемости; итоговые выводы.

Альпидовская М.Л. - научное руководство; разработка концепции исследования; утверждение окончательного варианта; итоговые выводы.

Contribution of the authors:

Bondarev M. A. - writing the source text; conducting a statistical study; developing a methodology; analyzing the income of the population, as well as a set of factors affecting its change; final conclusions.

Yakovleva E.E. - writing the source text; conducting statistical research; collecting and systematizing data; analyzing demographic statistics and calculating basic fertility rates; final conclusions.

Alpidovskaya M.L. - scientific guidance; development of the research concept; approval of the final version; final conclusions. 